УДК 691.618.93

doi: $10.18101 / 2306-2363-2017-2-3-3-11$

\title{
ПЕНОСТЕКЛО НА ОСНОВЕ МЕСТНОГО ГЛИНИСТОГО СЫРЬЯ И СТЕКЛОБОЯ: СТРУКТУРА И СВОЙСТВА
}

\author{
(C) Н. Н. Анчилоев \\ старший преподаватель, Восточно-Сибирский государственный университет \\ технологий и управления \\ Россия, 670013, Улан-Удэ, ул. Ключевская, 40в \\ E-mail: anchiloev@yandex.ru

\section{(С Д. Р. Дамдинова} \\ доктор технических наук, профессор, \\ Восточно-Сибирский государственный университет технологий и управления \\ Россия, 670013, Улан-Удэ, ул. Ключевская, 40в \\ E-mail: damdinova@mail.ru

\section{(C) В. Е. Павлов} \\ кандидат технических наук, \\ Восточно-Сибирский государственный университет технологий и управления \\ Россия, 670013, Улан-Удэ, ул. Ключевская, 40в \\ E-mail: pavlov.vpp@gmail.com
}

Для обеспечения современных требований к энергоэффективности зданий и сооружений показана актуальность использования эффективных теплоизоляционных материалов. Важной задачей является поиск новых путей получения теплоизоляционного материала - пеностекла при пониженных энерго- и ресурсных затратах. Приведены результаты исследований по разработке пеностекол системы «глина-стеклобой-гидроксид натрия». Применение глин обосновано распространенностью и химическим составом. Для снижения средней плотности пеностекол предложено использование термической активации глинистой породы, а для повышения прочности пеностекла - частичная замена стеклобоя перлитом. Получена регрессионная зависимость средней плотности пеностекол от рецептурнотехнологических факторов. Приведены результаты физико-химических исследований структуры сырьевых компонентов и пеностекол.

Ключевые слова: пеностекло, глина, стеклобой, перлит, теплоизоляционный материал, термическая активация, обжиг, уравнения регрессии, плотность, рентгенофазовый анализ.

Теплоизоляционные материалы, применяемые в строительстве жилых и промышленных зданий с целью уменьшения тепловых потерь в окружающую среду, выполняют ответственную функцию и становятся в один ряд по важности с несущими конструкциями. Это понимание заставляет очень тщательно подходить к выбору утеплителя здания. С точки зрения долговечности, огне- и биостойкости теплоизоляционные материалы неорганического происхождения имеют преимущество перед утеплителями органическими. Одним из таких неорганических материалов является пеностекло, теплоизоляционный материал, о котором известно с середины прошлого столетия и, который хорошо себя зарекомендовал в разных областях. О надежности пеностекла 
говорит то, что им утепляют обитаемые капсулы космических кораблей и подводные лодки. Но в строительстве и технике тепловая изоляция с помощью пеностекла не приобрела популярности из-за относительно высокой стоимости теплоизоляционного материала. Поэтому поиск новых технологических подходов в деле уменьшения энерго- и ресурсных затрат при производстве пеностекла является важной задачей.

В основе снижения производственных энергозатрат и усовершенствования технологий получения пеностекла лежит главным образом подбор исходных компонентов шихты, способных к плавлению в приемлемом с позиций энергозатрат температурном диапазоне. Принимая во внимание то, что температура обжига является определяющим фактором стоимости синтезируемого материала, приходим к тому, что обжиг должен проводиться в диапазоне температур обжига $\left(800 \ldots 900^{\circ} \mathrm{C}\right)$. В особенности это актуально для обжига пеностекол, обжигаемых в стальных формах, ибо с повышением максимальной температуры обжига возрастает потребность в жаростойкой стали для внутрипечного оборудования. В указанном диапазоне в качестве исходных материалов можно использовать техногенные продукты, такие как стеклобой, золошлаковые материалы, а также природные вулканические стекла, как например, перлиты. В качестве интенсификатора газообразования можно использовать щелочи, поскольку они, являясь одновременно интенсификаторами плавления, обеспечивают размягчение шихты при меньшей температуре. Щелочь в данном случае проявляет себя как химический активатор процесса поризации. При производстве пеностекол не обойтись также и без другого вида активации, как механоактивация.

Известно, что чем более закристаллизован компонент шихты, тем большая потребуется температура обжига. Это связано с тем, что чем крепче связь в структуре закристаллизованного вещества, тем большую энергию нужно потратить для разрушения связей типа силоксановых. Если разрушить такую связь до обжига на уровне измельчения, то можно заметно снизить рабочую температуру обжига. Поскольку закристаллизованные породы составляют большую часть всех запасов полезных ископаемых земной коры, их активация может значительно расширить палитру исходных компонентов для производства строительных материалов, в том числе и пеностекол.

Однако, получение пеностекол с использованием только закристаллизованных горных пород без добавления стекловидного материала в низких диапазонах температур обжига и без применения механоактивации является трудной задачей, о чем указано в работах $[1 ; 2]$. При получении пеностекол на основе минеральных сырьевых компонентов и стеклобоя рациональной состав стеклошихты включал компоненты с различным фазовым составом. Во время спекания стеклошихты при получении пеностекла в межпоровых стенках происходит заполнение пространства между кристаллами стекломассой, формируя тем самым прочную матрицу, в которой в стекловидном веществе распределены как аморфизированные кристаллические фазы, так и новообразованные. В результате такого процесса происходит увеличение прочности материала без существенного увеличения плотности, то есть улучшается коэффициент конструктивного качества теплоизоляционного материала. 
Н. Н. Анчилоев, Д. Р. Дамдинова, В. Е. Павлов. Пеностекло на основе местного глинистого сырья и стеклобоя: структура и свойства

Следует отметить, что варьируя соотношение кристаллической и стекловидной фазы в исходной шихте, мы получаем инструмент по моделированию структуры и свойств синтезируемого материала и в результате можем получать теплоизоляционные и конструкционно-теплоизоляционные материалы в рамках единого технологического пространства при производстве пеностекол.

Основной целью наших исследований является разработка составов и режимов обжига пеностекол на основе местных глин и стеклобоя. Основанием к рассмотрению глинистой породы в качестве компонента шихты для пеностекла послужили их фазовый и химический составы. При выборе этого вида сырья немаловажное значение имеет широкая их распространенность и гранулометрия. Как известно, глинистые породы, содержащие наночастицы глинистых и неглинистых минералов, оксидов железа, органического вещества с размерами меньше 100 нм, являются типичным представителем природных наноматериалов со своими наноструктурами [3].

Представляло интерес изучение влияния изменения структуры исходных компонентов шихты в результате повышения их реакционной способности путем механо- и щелочной активации на структуру и плотность пеностекол рассматриваемой системы «глина-стеклобой-гидроксид натрия». В качестве глинистой породы рассматривали глинистую породу Шенистуйского месторождения, в качестве стеклобоя - бой тарного стекла. В качестве щелочного активатора использовали гидроксид натрия (табл. 1).

Таблица 1

Химический состав сырьевых компонентов

\begin{tabular}{|l|c|c|c|c|c|c|c|c|c|}
\hline \multicolumn{1}{|c|}{ Сырье } & $\mathrm{SiO}_{2}$ & $\mathrm{Al}_{2} \mathrm{O}_{3}$ & $\mathrm{Fe}_{2} \mathrm{O}_{3}$ & $\mathrm{CaO}$ & $\mathrm{MgO}$ & $\mathrm{Na}_{2} \mathrm{O}$ & $\mathrm{K}_{2} \mathrm{O}$ & $\mathrm{SO}_{3}$ & п.п.п. \\
\hline $\begin{array}{l}\text { Глинистая } \\
\text { порода }\end{array}$ & 64,08 & 18,10 & 5,28 & 1,48 & 1,46 & - & - & 0,01 & 4,53 \\
\hline Стеклобой & 71,46 & 2,47 & 0,40 & 6,74 & 3,43 & 14,45 & 0,85 & 0,20 & - \\
\hline
\end{tabular}

п.п.п. - потери при прокаливании

Методика проведения экспериментов включала подготовку глинистой породы и стеклобоя путем дробления в щековой дробилке, а затем тонкого помола стеклобоя в виброистирателе ВИ 350 х 4 до удельной поверхности $\sim 350 \mathrm{M}^{2} / \mathrm{\kappa}$.

Для активации процесса поризации на этапе обжига, в глинистую породу добавляли гидроксид натрия в виде водного раствора требуемой концентрации, после чего смесь подвергали сушке в муфельной сушильной камере с максимальной рабочей температурой $350{ }^{\circ} \mathrm{C}$. В результате этого глиняное тесто приобретало вид конгломерата, который дробили, а затем измельчали в виброистирателе до удельной поверхности, сравнимой с удельной поверхностью стеклопорошка. После смешивания порошков, затворенных водой с добавлением некоторого количества жидкого стекла путем прессования формировали образцы в виде кубиков сторонами 3 х 3 х 3 см. Обжиг производили в электрокамерной печи ЭКПС-10 при различных температурах.

Для повышения прочности пеностекол в базовой шихте часть стеклобоя заменяли стекловидным перлитом Мухор-Талинского месторождения соста- 
ва, мас.\%: $\mathrm{SiO}_{2}-69,4 ; \mathrm{Al}_{2} \mathrm{O}_{3}-13,75 ; \mathrm{Fe}_{2} \mathrm{O}_{3}-0,5 ; \mathrm{FeO}-0,06 ; \mathrm{CaO}-0,5$; $\mathrm{MgO}-0,3 ; \mathrm{TiO}_{2}-0,15 ; \mathrm{Na}_{2} \mathrm{O}-3,37 ; \mathrm{K}_{2} \mathrm{O}-3,91 ; \mathrm{SO}_{3}-0,1$ и п.п.п. 5,97. Частичная замена стеклобоя стекловидным перлитом имеет целесообразность также в том случае, если на уровне производства возникнут перебои с поставками стеклобоя.

На рис. 1 показаны графики зависимости средней плотности синтезируемого пеноматериала от температуры обжига при использовании одной и той же шихты по содержанию глинистой породы и стеклобоя, отличающейся тем, что в контрольной шихте использована глинистая порода без термической активации, а во второй - с термоактивацией. В случае использования неактивированной глины, раствор щелочи вводили после перемешивания порошков глины и стеклобоя, в случае использования активированной глины раствор щелочи вводили в активируемую глину.

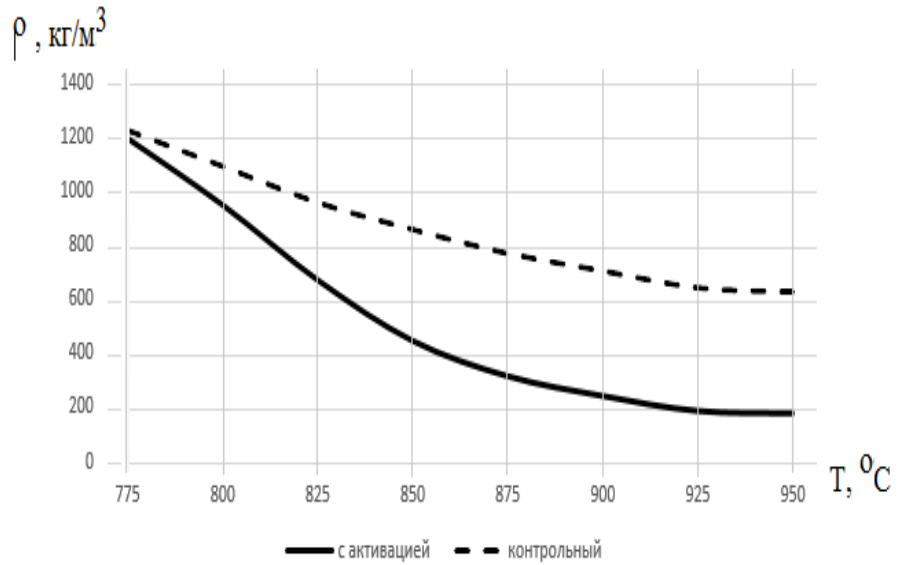

Рис. 1. Графики зависимости средней плотности пеноматериала от температуры обжига

Анализ характера полученных зависимостей указывает на то, что термохимическая активация глинистой породы позволяет значительно понизить среднюю плотность пеностекол в диапазоне температур 800-900 ${ }^{\circ} \mathrm{C}$ при одинаковом уровне щелочного компонента в среднем равном 9-10\%. Во время обжига используемая для склейки щелочь играет роль плавня и газообразователя. То есть в рамках такой технологической операции как активация, щелочь является своего рода катализатором - способствует активации процесса поризации, при этом находясь по содержанию на постоянном уровне.

При затворении щелочным раствором глинистой породы и последующей ее сушке происходит склейка чешуек глины. Очевидно, что прочность такой склейки меньше, чем прочность кристаллической связи минералов, входящих в состав глины, и при длительном неинтенсивном помоле, например, в шаровой мельнице, такая склейка разрушится в первую очередь. Другое дело, когда в нашей работе систему подвергают механоактивации в вибрационном измельчителе. Из курса сопротивления материалов известно понятие об условно-мгновенной или динамической прочности, зависящей от времени 
Н. Н. Анчилоев, Д. Р. Дамдинова, В. Е. Павлов. Пеностекло на основе местного глинистого сырья и стеклобоя: структура и свойства

воздействия на материал и связей в нем: чем это время воздействия меньше, тем больше динамическая прочность.

Известно, что эффективность механоактивации растет экспоненциально среднему размеру частиц истираемого вещества: чем крупнее частица, тем больше будет рост числа дислокаций после обработки и, наоборот, чем меньше частица, тем меньше рост этих дислокаций, что косвенно наблюдали, проводя эксперимент. При механоактивации воздействие на частицыизмельчаемого материала измеряется десятитысячными долями секунды, что позволяет достигнуть такой прочности склейки, которая может быть сопоставима с межкристаллической связью. Поэтому, по мнению авторов, наряду с разрушением склейки между чешуйками глины происходит разрушение самой чешуйки в виде разрыва силоксановых связей.

Косвенным подтверждением предположения авторов является, то, что примененная активация работает и для других закристаллизованных пород, в рамках эксперимента были активированы базальт и цеолит, причем для стекловидных компонентов такая активация не дает эффекта.

Следует отметить, что сушка кристаллической породы является определяющим фактором для склейки материала. Так, сушка в естественных условиях или температуре менее $100{ }^{\circ} \mathrm{C}$ не дает желаемого результата даже при увеличении продолжительности сушки. Поэтому для более подробного изучения процесса активации глинистой породы был реализован ротатабельный план второго порядка Бокса-Хантера для $\mathrm{k}=5$.

В качестве факторов были приняты: содержание глины активированной $x_{1}$, масс.\%, содержание перлита $x_{2}$ масс.\%, продолжительность термоактивации $x_{3}$, мин., температура сушки $x_{4},{ }^{\circ} \mathrm{C}$, температура обжига $x_{5},{ }^{\circ} \mathrm{C}$.

Для получения пеностекол была рассмотрена шихта, в состав которой включена глина в пределах $15-75 \%$ от навески (30 г). Разница между массой навески и массой глины распределялась между перлитом и стеклобоем таким образом, что содержание перлита при этом варьировалось в пределах $15-75 \%$ от вышеуказанной разницы масс навески и глины, а содержание стеклобоя соответственно варьировалось в пределах $25-85 \%$ от этой разницы. Для оценки роли перлита содержание перлита при математическом планировании включено в качестве фактора, а стеклобой присутствует по умолчанию в скрытом виде. Щелочной компонент принят на постоянном для глины уровне в пределах $20 \%$ от массы глины. В пересчете на всю массу шихты содержание гидроксида натрия (поскольку содержание глины варьируется в эксперименте) колеблется в пределах от 3 до 13\%.

Условия планирования представлены в табл. 2.

Таблица 2

Ротатабельный план второго порядка для $k=5$

\begin{tabular}{|c|c|c|c|c|c|c|}
\hline № & Фактор & -2 & -1 & 0 & +1 & +2 \\
\hline 1 & Содержание глины активированной, \% & 15 & 30 & 45 & 60 & 75 \\
\hline 2 & Содержание перлита, \% & 15 & 0,3 & 0,45 & 0,6 & 0,75 \\
\hline 3 & Продолжительность активации, мин & 30 & 45 & 60 & 75 & 90 \\
\hline 4 & Температура активации, ${ }^{\circ} \mathrm{C}$ & 150 & 200 & 250 & 300 & 350 \\
\hline 5 & Температура обжига, ${ }^{\circ} \mathrm{C}$ & 825 & 850 & 875 & 900 & 925 \\
\hline
\end{tabular}


По результатам проведенного эксперимента было получено уравнение регрессии, которое после исключения незначимых факторов имеет вид: $\mathrm{y}=643,24 \mathrm{x}_{0}-39,28 \mathrm{x}_{1}+185,40 \mathrm{x}_{2}-14,26 \mathrm{x}_{3}+22,68 \mathrm{x}_{4}-68,14 \mathrm{x}_{5}-23,67 \mathrm{x}_{1}{ }^{2}-21,93 \mathrm{x}_{2}{ }^{2}+$ $59,19 \mathrm{x}_{3}{ }^{2}+90,12 \mathrm{x}_{4}{ }^{2}-17,06 \mathrm{x}_{5}^{2}-70,75 \mathrm{x}_{1} \mathrm{x}_{2}+18,5 \mathrm{x}_{1} \mathrm{x}_{3}-35,38 \mathrm{x}_{1} \mathrm{x}_{5}-37,5 \mathrm{x}_{3} \mathrm{x}_{4}$

Судя по уравнению, повышение содержания активированной глины способствует снижению плотности в образцах пеностекла. Это объясняется тем, что активированная глина вносит с собой в шихту и шелочь, причем, чем выше содержание глины в шихте, тем больше вносится в шихту щелочного компонента. Рентгенофазовый анализ показал, что исходная не подогретая глина характеризуется наличием рефлексов монтмориллонита, кварца, кристобалита, полевых шпатов. Структура активированной глины после сушки характеризуется наличием дополнительного рефлекса с $\mathrm{d} / \Pi=0,6324 ; 0,3658$ нм, соответствующего щелочному алюмосиликату, подобному природному минералу - содалиту (рис. 2).

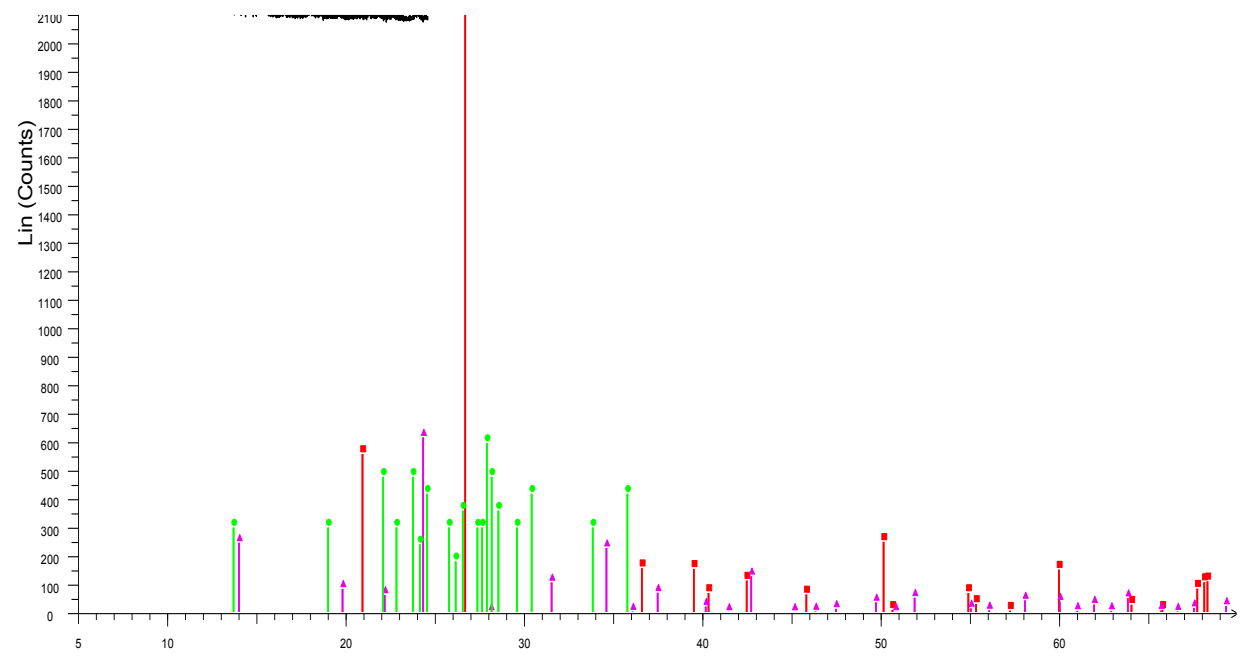

2-Theta - Scale

WGlina 150-30 - File: 2017-03-24 \#9.raw - Type: 2Th/Th locked - Start: $5.000^{\circ}$ - End: $69.990^{\circ}$ - Step: 口01-087-2096 (C) - alpha-SiO2 - Y: 93.78 \% - Quartz low - d x by: 1. - WL: 1.5406 - Hexagonal - a 4.

$\Delta$ 01-086-1030 (C) - Na7.89(AISiO4)6(NO3)1.92 - Y: $22.40 \%$ - Sodalite ((N O3)-exchanged), syn - d x

$000-010-0360$ (D) - (Ca,Na)(Si,Al)4O8 - Y: $21.70 \%$ - Anorthite, sodian, disordered, syn - d x by: 1. -

Рис. 2. Рентгенограмма глины с использованием активации

В отношении влияния перлита выявлено, что увеличение содержания его в составе, равно как и уменьшение содержания стеклобоя способствует повышению показателя средней плотности пеностекла. Этот результат можно использовать как один из способов управления структурой и свойствами пеностекол.

Анализ влияния продолжительности и температуры термоактивации глины на плотность пеностекол показал, что между указанными факторами и функцией отклика $y$ существует квадратичная зависимость с экстремумом, что свидетельствует о наличии оптимальных уровней факторов (рис. 3). 
По литературным данным [4], на дериватограммах глин различных месторождений в области температур $120-350{ }^{\circ} \mathrm{C}$ отмечается эндоэффект с пиком при температурах 160 и $170{ }^{\circ} \mathrm{C}$, связанный с удалением адсорбированной воды. Очевидно аналогичный процесс происходит в диапазоне температур 150 $350{ }^{\circ} \mathrm{C}$ и в наших исследованиях. Посколькуимеется пик эндоэффекта на дериватограмме, соответствующий минимум мы наблюдаем и на поверхности отклика, отражающего зависимость плотности пеностекла от температурновременных режимов термоактивации глинистой породы. Целесообразность предварительного удаления физически связанной адсорбированной воды из структуры глины в данной работе обосновывается тем, что на последующей технологической стадии обжига избыточная влага, как правило, приводит к нарушению сплошности вспениваемого образца, и как следствие, к ухудшению структуры и свойств пеностекол. Анализ структуры материала после обжига показал аморфизацию кристаллических фаз, о чем свидетельствуют значительное снижение на рентгенограммах пеностекол интенсивностей пиков, соответствующих кварцу и исчезновение рефлексов содалита - новообразованного соединения при термоактивации глины, затворенного раствором гидроксида натрия.

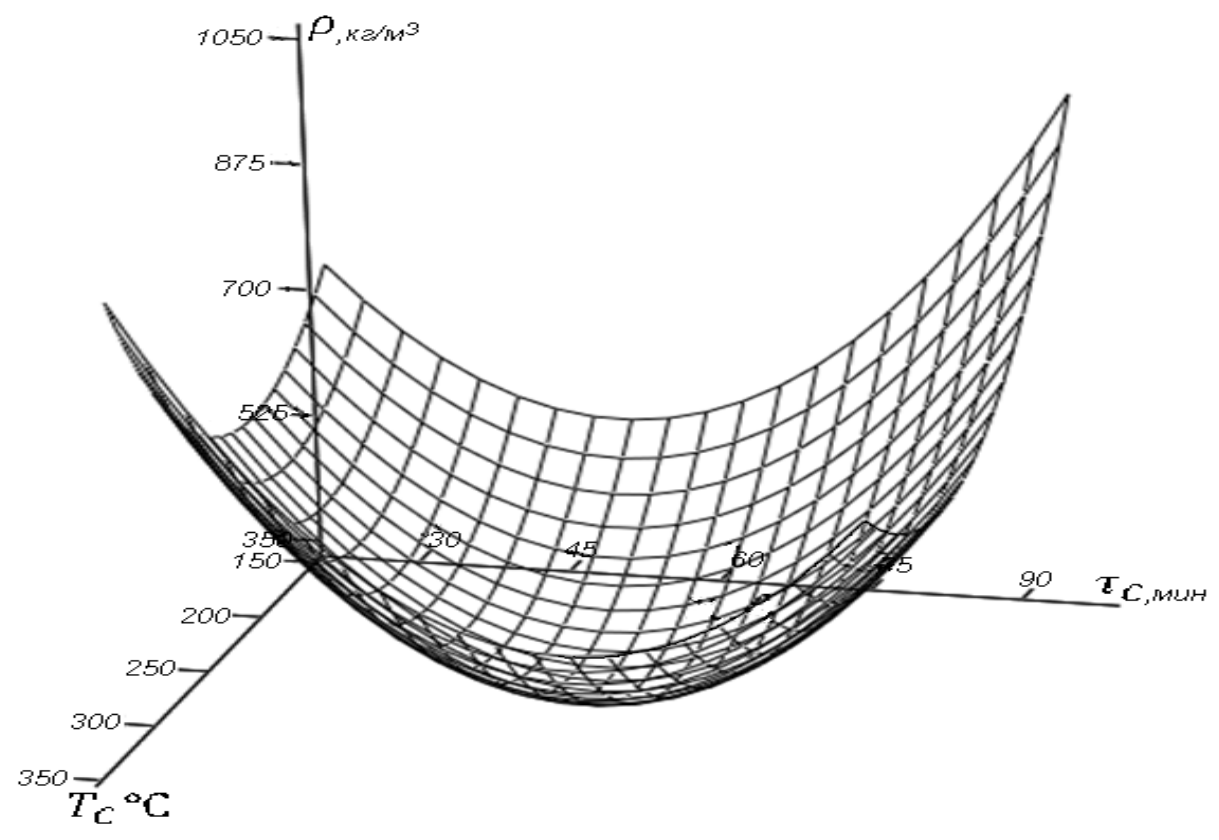

Рис. 3. График зависимости средней плотности пеностекол от продолжительности и температуры активации

Таким образом, проведенные исследования позволяют сделать следующие выводы:

- показана возможность получения в температурном диапазоне от 850 до $900{ }^{\circ} \mathrm{C}$ пеностекол на основе глинистой породы и стеклобоя с добавлением щелочного компонента; 
- установлена целесообразность использования наряду с ранее применяемыми методами механо- и щелочной активации термической активации глинистой породы;

- получено уравнение регрессии, устанавливающее зависимость плотности пеностекла от содержания исходных компонентов шихты, температурных режимов активации и обжига;

- с применением рентгенофазового анализа исследованы структуры исходной и активированной глин и пеностекол системы «глина-стеклобойгидроксид натрия»;

- доказана принципиальная возможность получения пеностекол со средней плотностью 350-700 кг/ $\mathrm{m}^{3}$ и прочностью до 3,2 МПа.

\section{Литература}

1. Дамдинова Д. Р. Пеностекло с повышенными конструктивными свойствами на основе стеклобоя и эффузивных пород // Изв. ВУЗов. Строительство. - 2006. № 11-12. - С. 35-42.

2. Дамдинова Д. Р., Павлов В. Е., Анчилоев Н. Н. Пеностекла системы «стеклобой-глина-гидроксид натрия»: составы, структура и свойства // Строительные материалы. - 2014. - № 8. - С. 38-40.

3. Соколов В. Н., Чернов М. С. Минеральные наноструктуры глинистых пород// Доклады академических наук. — 2013. - № 2. - С. 196-198.

4. Коношенко Г. И. Мухина В. К., Петрихина Г. А. и др. Влияние режима термообработки вспучивающихся пород в печи кипящего слоя на свойства пористых песков // Сб. трудов ВНИИСтром. - М., 1973. — Вып. 27(55). — С. 82-87.

FOAMGLASS BASED ON THE LOCAL CLAY RAW MATERIALS AND CALLET: STRUCTURE AND PROPERTIES

\section{N. N. Anchiloev}

Senior Lecturer, Chair of Materials Resistance,

East Siberia State University of Technology and Management

Russia, 670031, Ulan-Ude, Klyuchevskaya Str., 40v

\section{R. Damdinova}

Doctor of Technical Sciences, Professor,

East Siberia State University of Technology and Management

Russia, 670013, Ulan-Ude, Klyuchevskaya Str., 40v

V. E. Pavlov

candidate of Technical Sciences,

East Siberia State University of Technology and Management

Russia, 670031, Ulan-Ude, Kluuchevskaya Str., 40v

To ensure modern requirements for energy efficiency of buildings and structures, the relevance of the use of effective heat-insulating materials is shown. An important task is to find new ways of obtaining a heat-insulating material - foam glass with reduced energy and resource costs. The results of research on the development of foam glass of the "clay-cullet-sodium hydroxide" system are given. The use of clays is justified by the prevalence and chemical composition. To reduce the average density of foamed glasses, the use of thermal activation of clay rock is suggested, and to increase the strength of 

стого сырья и стеклобоя: структура и свойства

foam glass, a partial replacement of cullet with perlite is suggested. The regression dependence of the average density of foamed glasses on prescription and technological factors is obtained. The results of physical and chemical studies of the structure of raw components and foamed glass are presented.

Keywords: foamed glass, clay, cullet, perlite, thermal insulation material, thermal activation, calcination, regression equations, density, X-ray phase analysis. 